Supplement of Biogeosciences, 18, 1417-1437, 2021 https://doi.org/10.5194/bg-18-1417-2021-supplement (C) Author(s) 2021. This work is distributed under the Creative Commons Attribution 4.0 License.

(c) (1)

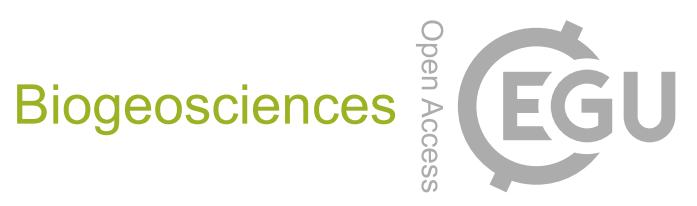

Supplement of

\title{
Spatio-temporal variations in lateral and atmospheric carbon fluxes from the Danube Delta
}

Marie-Sophie Maier et al.

Correspondence to: Marie-Sophie Maier (marie-sophie.maier@usys.ethz.ch)

The copyright of individual parts of the supplement might differ from the CC BY 4.0 License. 


\section{S1 Methods}

\section{S1.1 Information on sampling stations}

Table S1 Name, waterscape and geographical location of all investigated sampling stations. $\mathbf{R}$ indicates river stations, $\mathrm{C}$ are channel stations and $L$ represent lake stations. Station 16 was sampled only once due to insufficient accessibility by motor boat and is therefore excluded from the dataset in this paper.

\begin{tabular}{|c|c|c|c|c|}
\hline Station & waterscape & Name & latitude & longitude \\
\hline 1 & $\mathrm{R}$ & Patlageanca & 45.21841 & 28.75167 \\
\hline 2 & $\mathrm{R}$ & Mila 35 & 45.19757 & 28.87490 \\
\hline 3 & $\mathrm{R}$ & Chilia $^{\text {a }}$ & 45.25218 & 29.66011 \\
\hline 4 & $\mathrm{R}$ & Sulina ${ }^{b}$ & $\begin{array}{l}45.16231^{*} \\
45.15790^{* *}\end{array}$ & $\begin{array}{l}29.72729 \\
29.63783^{* *}\end{array}$ \\
\hline 5 & $\mathrm{R}$ & St. Gheorge & 44.89552 & 29.58627 \\
\hline 6 & $\mathrm{C}$ & Channel St. Gheorge & 44.90902 & 29.58842 \\
\hline 7 & $\mathrm{~L}$ & Lake Puiu & 45.05563 & 29.48437 \\
\hline 8 & $\mathrm{~L}$ & Lake Rosu & 45.05398 & 29.56852 \\
\hline 9 & $\mathrm{C}$ & Channel Sulina & 45.15544 & 29.61046 \\
\hline 10 & $\mathrm{C}$ & Channel Impututa & 45.12802 & 29.59182 \\
\hline 11 & $\mathrm{C}$ & Old Danube M2 & 45.18104 & 29.47730 \\
\hline 12 & $\mathrm{R}$ & Crisan & 45.17247 & 29.47278 \\
\hline 13 & $\mathrm{~L}$ & Lake Bogdaproste & 45.23381 & 29.35933 \\
\hline 14 & $\mathrm{~L}$ & Lake Isac & 45.11264 & 29.27449 \\
\hline 15 & $\mathrm{R}$ & Murighiol & 45.04322 & 29.19678 \\
\hline 16 & $L$ & Lake Tataru & 45.03686 & 29.61423 \\
\hline 17 & $\mathrm{C}$ & Old Danube M1 & 45.18274 & 29.34535 \\
\hline 18 & $\mathrm{C}$ & Caraorman Channel & 45.12280 & 29.38938 \\
\hline 19 & $\mathrm{~L}$ & Lake Uzlina & 45.09096 & 29.26453 \\
\hline 20 & $\mathrm{~L}$ & Lake Rosulet & 45.07309 & 29.61386 \\
\hline
\end{tabular}

${ }^{\text {a }}$ Due to the border with Ukraine, this station had to be shifted to a small side branch of the Chilia branch. Comparative measurements showed no difference from the main branch.

${ }^{\mathrm{b}}$ The Sulina station was shifted upstream end of February 2016, since a continuously measuring sensor indicated influence of the Black Sea water: ${ }^{*}$ old location, ${ }^{* *}$ new location 


\section{S1.2 Evaluation of $\mathrm{CH}_{4}$ concentrations and fluxes}

\section{S1.2.1 comparability of $\mathrm{CH}_{4}$ concentration measurements}

In October 2017, we conducted a comparison of $\mathrm{CH}_{4}$ measurement procedures using the $\mathrm{GC}$ and the Los Gatos using field samples from the Danube Delta. We calculated average values for the lab-based GC procedure $(n=2)$ and the field-based LG

5 procedure $(\mathrm{n}=3)$. Considering the standard deviation of the samples, only 2 samples deviate from the 1:1 line, however they are still within the $10 \%$ measurement uncertainty of our GC system. Based on the results of this comparison, we deemed it appropriate to pool data acquired using the two different methods.

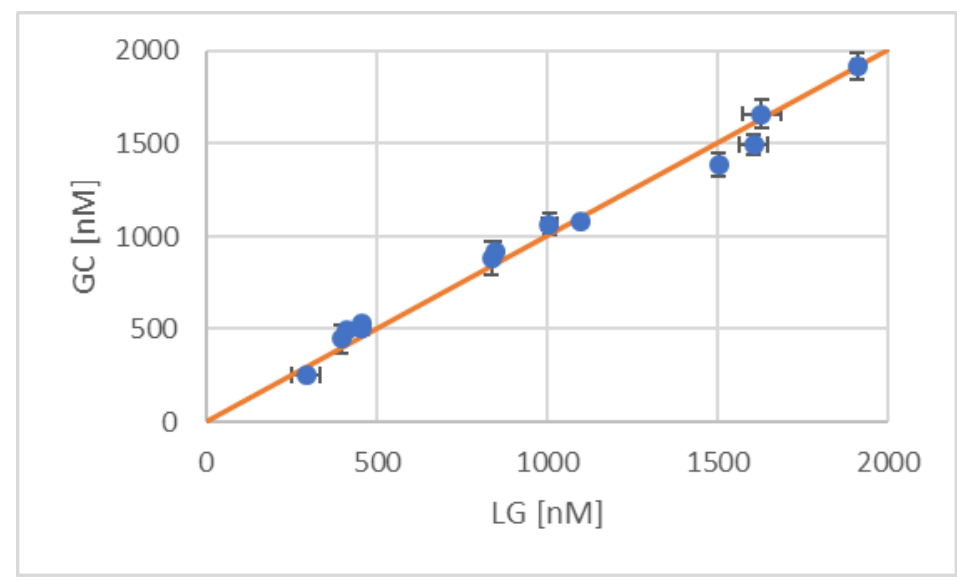

Figure 1 Average $\mathrm{CH}_{4}$ concentration measured with lab-based GC method $(\mathrm{n}=2)$ versus field-based LG method (n=3). Error bars show the standard deviation, the orange line symbolizes the 1:1 line.

\section{S1.2.2 evaluation of $\mathrm{CH}_{4}$ fluxes}

The following examples document the evaluation of $\mathrm{CH}_{4}$ fluxes from discrete samples (Fig S2), which were measured using

10 GC-FID (Aglient Technologies, USA). Continuous measurements (Fig. S3) in the headspace of the chamber were performed with an Ultraportable $\mathrm{CH}_{4} / \mathrm{N}_{2} \mathrm{O}$ analyzer (Los Gatos Research, USA). 

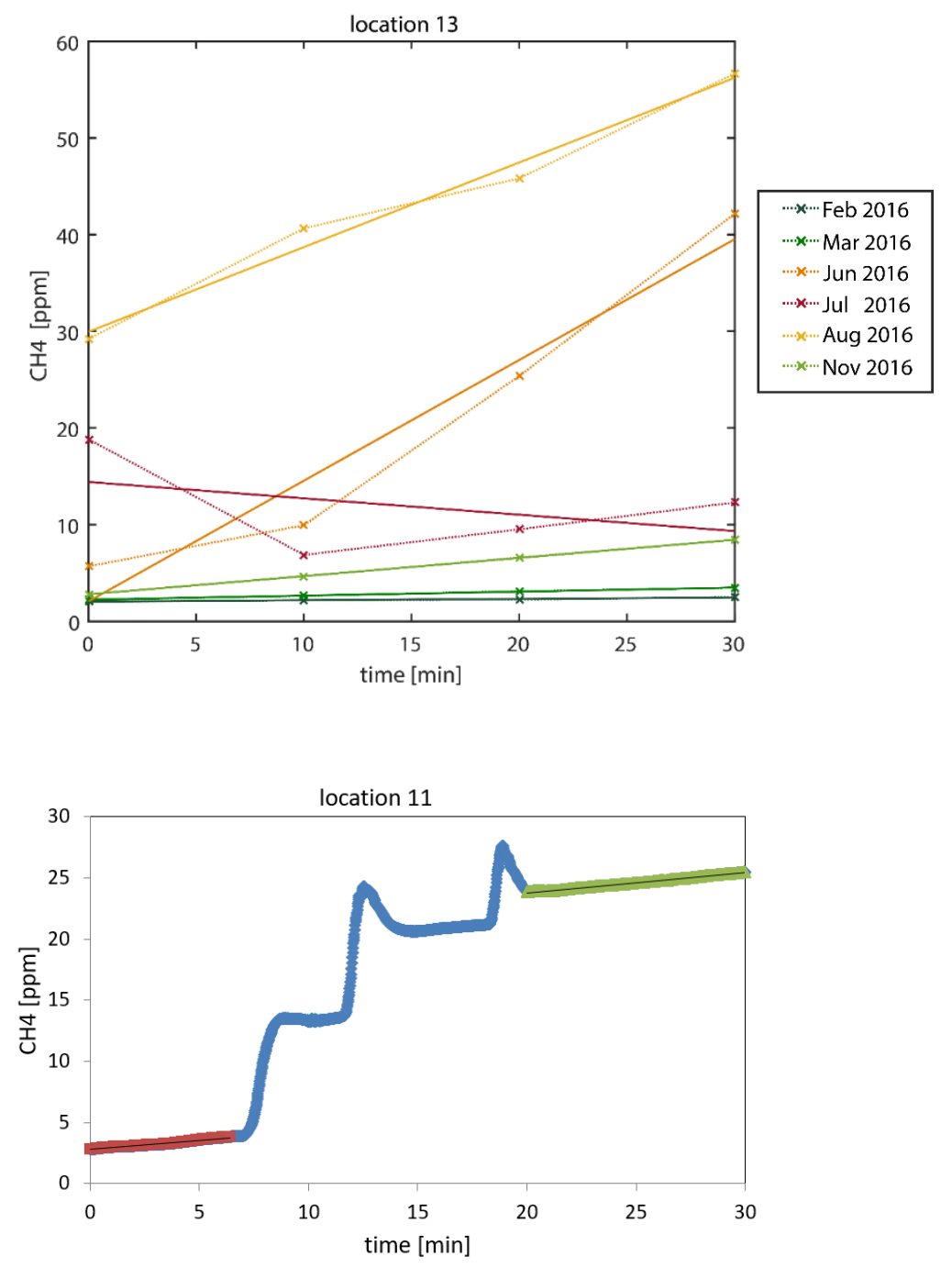

Figure S2 Flux measurements at location 13 highlighting the 3 different cases encountered during data evaluation. Dotted lines link individual measurements (x), solid lines show the calculated regression line. Green: linear fluxes with $R^{2}>0.96$, which we interpreted as diffusive $\mathrm{CH}_{4}$ fluxes. Yellow and orange: fluxes that had an $R^{2}<0.96$ and therefore were categorized to show signs of ebullition. Estimated fluxes were therefore reported as total fluxes. The diffusive contribution was estimated from $\mathrm{CH}_{4}$ water concentration and $\mathrm{k}_{600}$, which we derived from $\mathrm{CO}_{2}$ flux measured at the respective time and location. Dark red: non-monotonous flux, either by capturing a bubble or mislabelling a sample. Such timeseries were not included in the further analysis.

Figure S3 Continuous flux measurement with the Ultraportable $\mathrm{CH}_{4} / \mathrm{N}_{2} \mathrm{O}$ analyser at location 11 in September 2017. Diffusive fluxes are indicated in red and green, while the blue section shows sharp increases that indicate ebullition. Depending on the ebullitive flux, the system responded with overshooting. Diffusive fluxes were determined via the slope of the regression line of intervals where no influence of ebullition was observed. The total flux was determined by the overall concentration increase during the observed time interval (e.g. Beaulieu et al., 2016). 


\section{S2 Results}

\section{S2.1 Comparison of observed temperature and conductivity to long-term data from ICPDR}

Comparison of our measurements upstream of Tulcea with long-term observations from Reni (data from ICPDR, 2018) show that our observations are well within the range of previous measurements (Figure S4). Temperature was warmer in July, August

5 and September 2016 and 2017 than the long-term average.
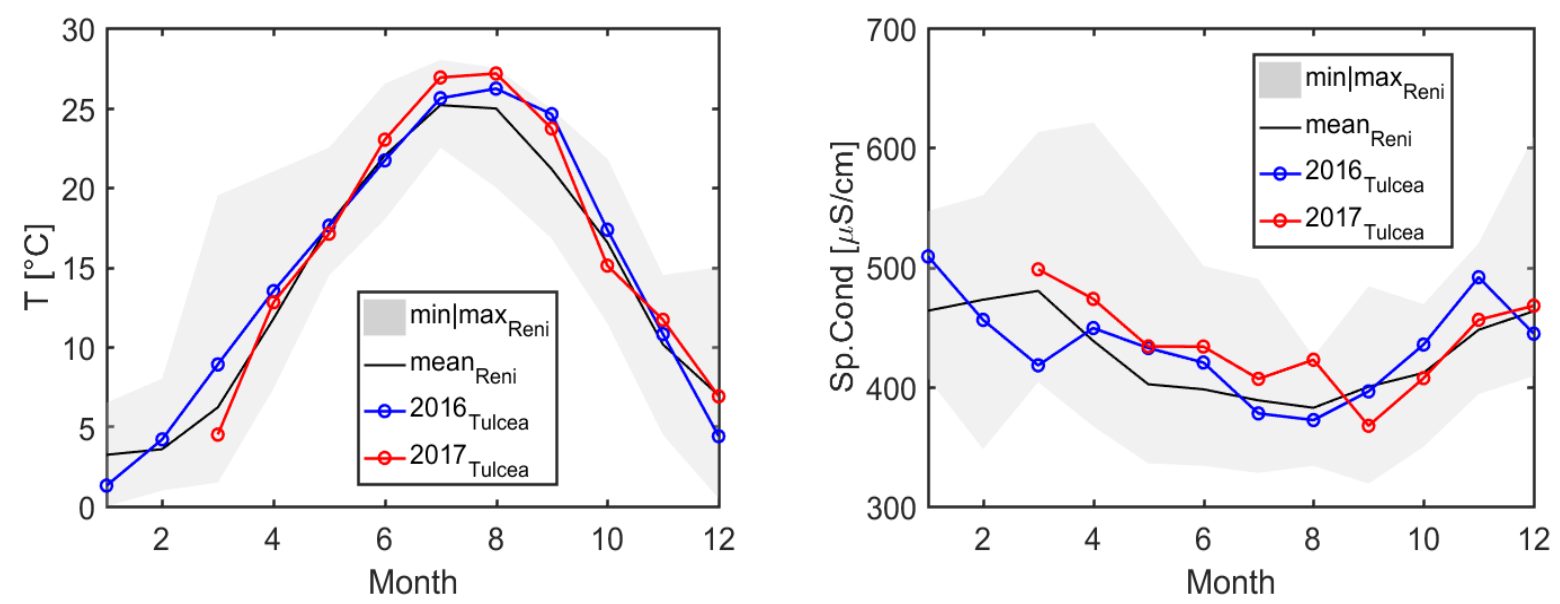

Figure S4 Seasonal development of temperature and specific conductivity. The blue and red line show our monthly observations in the Danube upstream of Tulcea in $\mathbf{2 0 1 6}$ and 2017, respectively. The black line represents the average of monthly to biweekly measurements in the period January 1996 to December 2014 in the case of temperature and July 1996 to December 2014 in the case of specific conductivity (ICPDR, 2018). 
S2.2 Seasonality of carbon import and export

Import and Export loads varied seasonally, which was to a large extent driven by variations in discharge (Fig. S5).
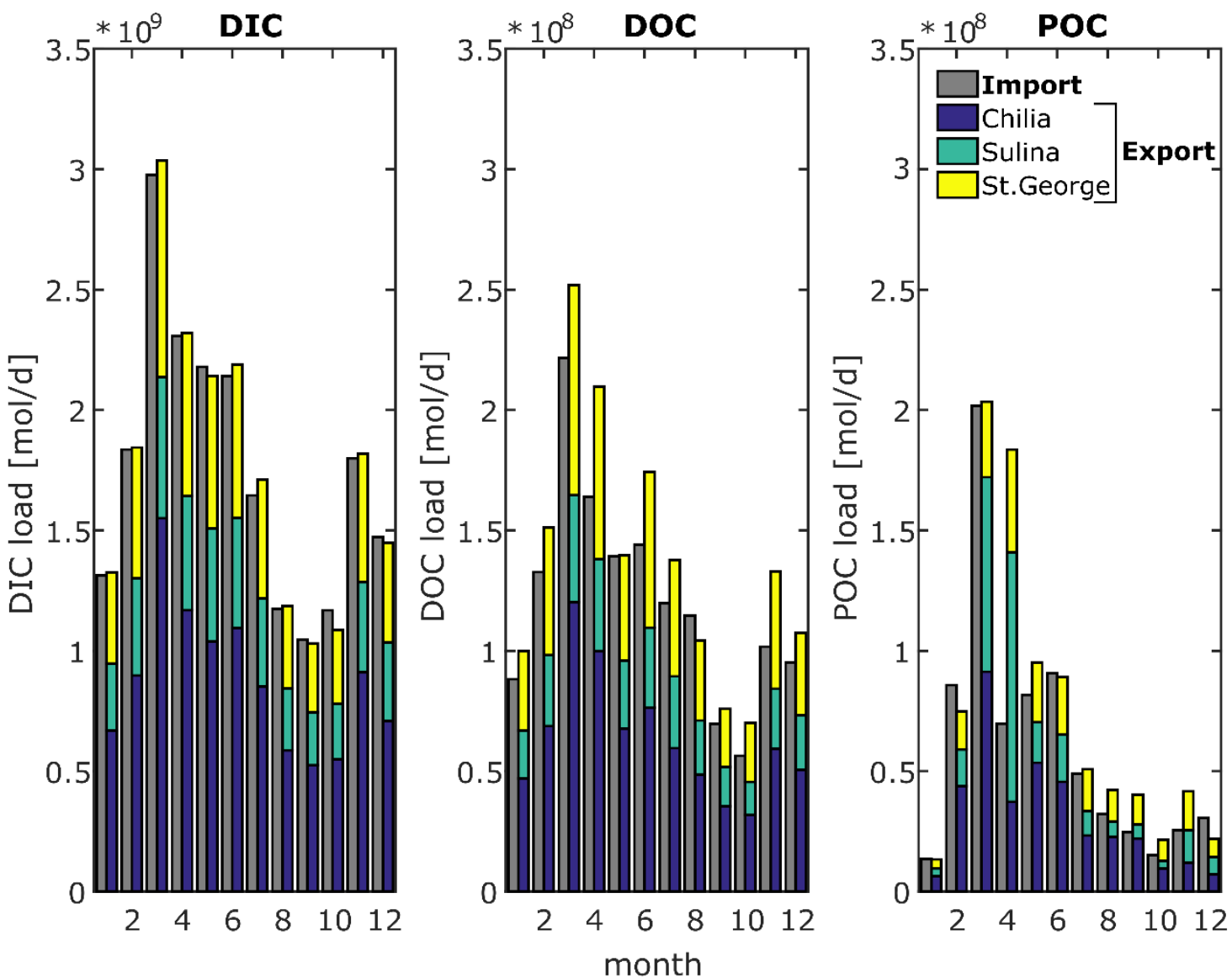

Figure S5 Carbon import to the delta and export to the Black Sea (sum of Chilia, Sulina and St. George branch) in the forms of DIC, 5 DOC and POC loads. Please observe the different order of magnitude for DIC. 


\section{S2.3 Visual results of Kruskal-Wallis Test}

We visualized the results of the multiple comparison test after Dunn-Sidak based on statistical data obtained from the KruskalWallis test using the multcompare function in Matlab. Most parameters are significantly different in the channels and lakes within the Danube delta compared to the river reaches outside. The time series of POC seems to be similar in lakes and the

5 river, however closer inspection indicates that this coincidence may be caused by different POC sources, specifically the spring peak during high sediment transport in the river and the summer peak during algal bloom in the delta lakes.
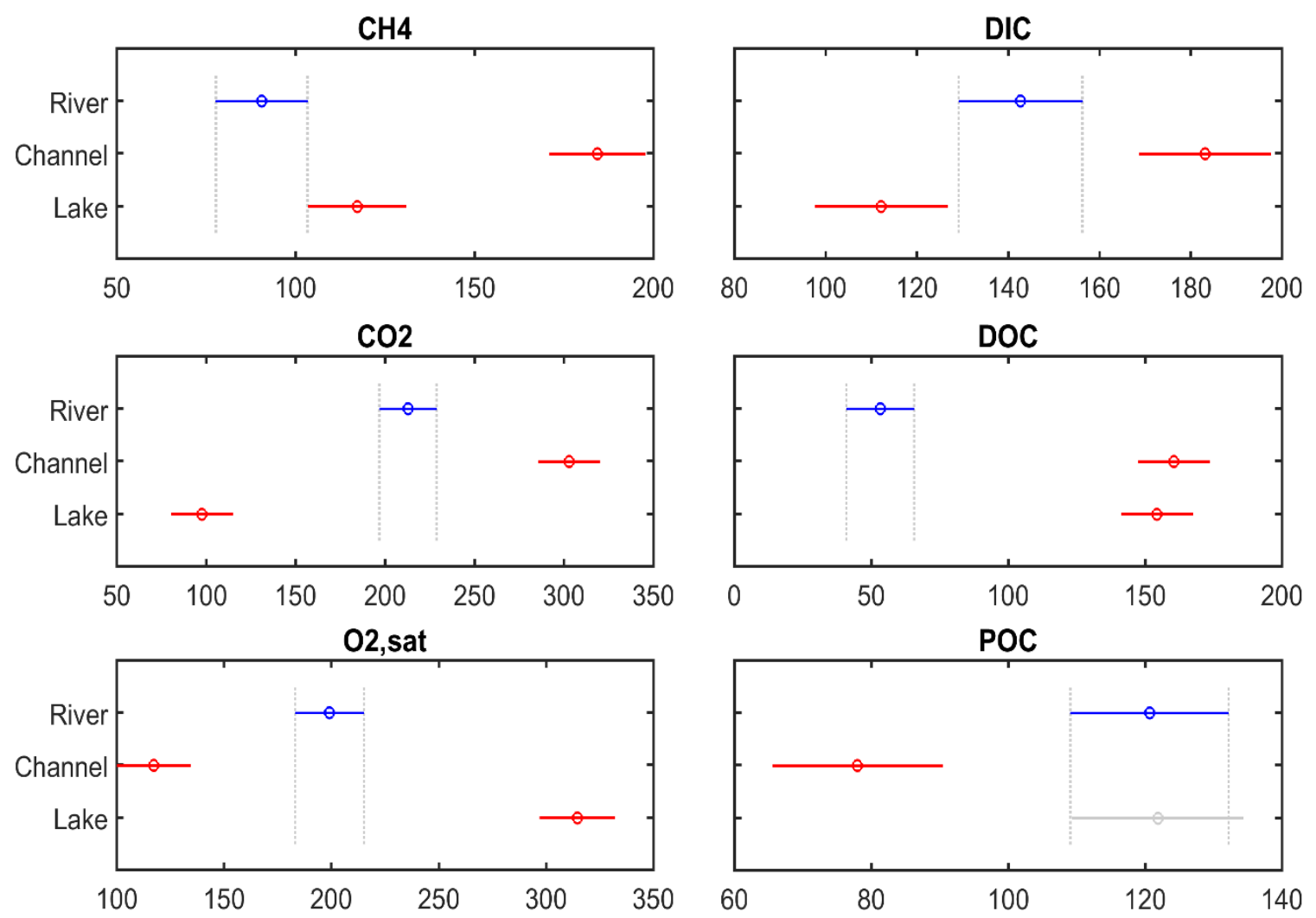

Figure S6 Visualization of results from Kruskal-Wallis non-parametric test for equal medians followed by Dunn-Sidak multiple comparison testing. Circles indicate the group mean, non-overlapping horizontal bars show significant difference: The channels and lakes in red are significantly different from the blue river group. Grey indicates no significant difference. The $x$-axis shows the average group ranks from the Kruskal-Wallis test. 


\section{S3 Discussion}

\section{$\mathrm{S3.1}_{\mathrm{CO}_{2}}$ and $\mathrm{CH}_{4}$ fluxes upscaled for three different waterscapes}

In the main text, Figure 5 illustrates the $\mathrm{CO}_{2}$ and $\mathrm{CH}_{4}$ fluxes from the different waterscapes to the atmosphere estimated from our monthly measurements. Below, Table S2 displays the numbers that are underlying the bar graphs in Figure 5, where the

5 height of the bar indicates results based the median fluxes, while the minimum and maximum extension of the black lines show the range resulting from calculations with 25 and 75 percentiles, respectively.

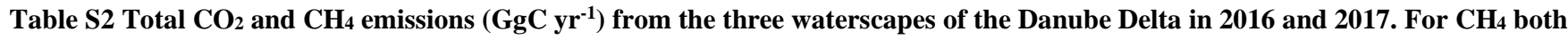
diffusive and total fluxes are displayed. Because of large gaps in $\mathrm{CH}_{4}$ data no fluxes were calculated for 2017.

\begin{tabular}{l|rc|rc|rc|cc}
\hline \multicolumn{1}{c|}{ Flux } & \multicolumn{2}{|c|}{ River } & \multicolumn{2}{c|}{ Channel } & \multicolumn{2}{c}{ Lake } & \multicolumn{2}{c}{ Total } \\
{$\left[\mathbf{G g C ~ y r}^{-1}\right.$ ] } & median & range & median & range & median & range & median & range \\
\hline $\mathbf{C O}_{\mathbf{2}, \mathbf{2 0 1 6}}$ & 22 & $16-30$ & 19 & $12-36$ & 19 & $4.6-45$ & 59 & $32-111$ \\
$\mathbf{C O}_{2,2017}$ & 18 & $15-22$ & 8.4 & $3.0-19$ & -3.3 & $-15-12$ & 23 & $3.2-54$ \\
\hline $\mathbf{C H}_{4, \text { dif, 2016 }}$ & 0.25 & $0.13-0.36$ & 0.16 & $0.11-0.48$ & 0.79 & $0.52-1.9$ & 1.2 & $0.76-2.8$ \\
$\mathbf{C H}_{4, \text { tot, 2016 }}$ & 0.25 & $0.15-0.39$ & 0.22 & $0.13-0.95$ & 3.1 & $0.77-6.9$ & 3.6 & $1.0-8.3$ \\
\hline
\end{tabular}




\section{S3.2 Respiratory $\mathrm{CO}_{2}$ production rate vs $\mathrm{CO}_{2}$ flux}

$\mathrm{CO}_{2}$ production rates were estimated from incubations for $\mathrm{O}_{2}$ community respiration and compared to measured $\mathrm{CO}_{2}$ fluxes for river (Fig. S7), channel (Fig. S8) and lake stations (Fig. S9). $\mathrm{CO}_{2}$ fluxes $\left(\mathrm{F}_{\mathrm{CO} 2}\right)$ marked with a triangle were calculated using the median $\mathrm{k}_{600}$ from the measurements in the respective waterscape. Dark purple bars represent measured respiration

5 rates $(\mathrm{R})$, light purple bars indicate the effect of a correction with a factor of 2.7 for measurement limitations using BOD bottles ( $\mathrm{R}_{\text {corBOD}}$ ) according to Ward et al. (2018). Station numbers refer to the sampling locations displayed in Figure 1 in the main text and documented further in Table $\mathrm{S} 1$.

While respiration rate exceeds $\mathrm{CO}_{2}$ flux in most cases in the River stations, the opposite is the case at many occasions in the channels, especially in the first half of the year until July. Respiration rates lower than $\mathrm{CO}_{2}$ flux indicate an additional $\mathrm{CO}_{2}$

10 source $\mathrm{CO}_{2}$ source. The channels are in close contact with adjacent reed beds, and lateral inflow from these wetlands could explain the $\mathrm{CO}_{2}$ excess. 
River
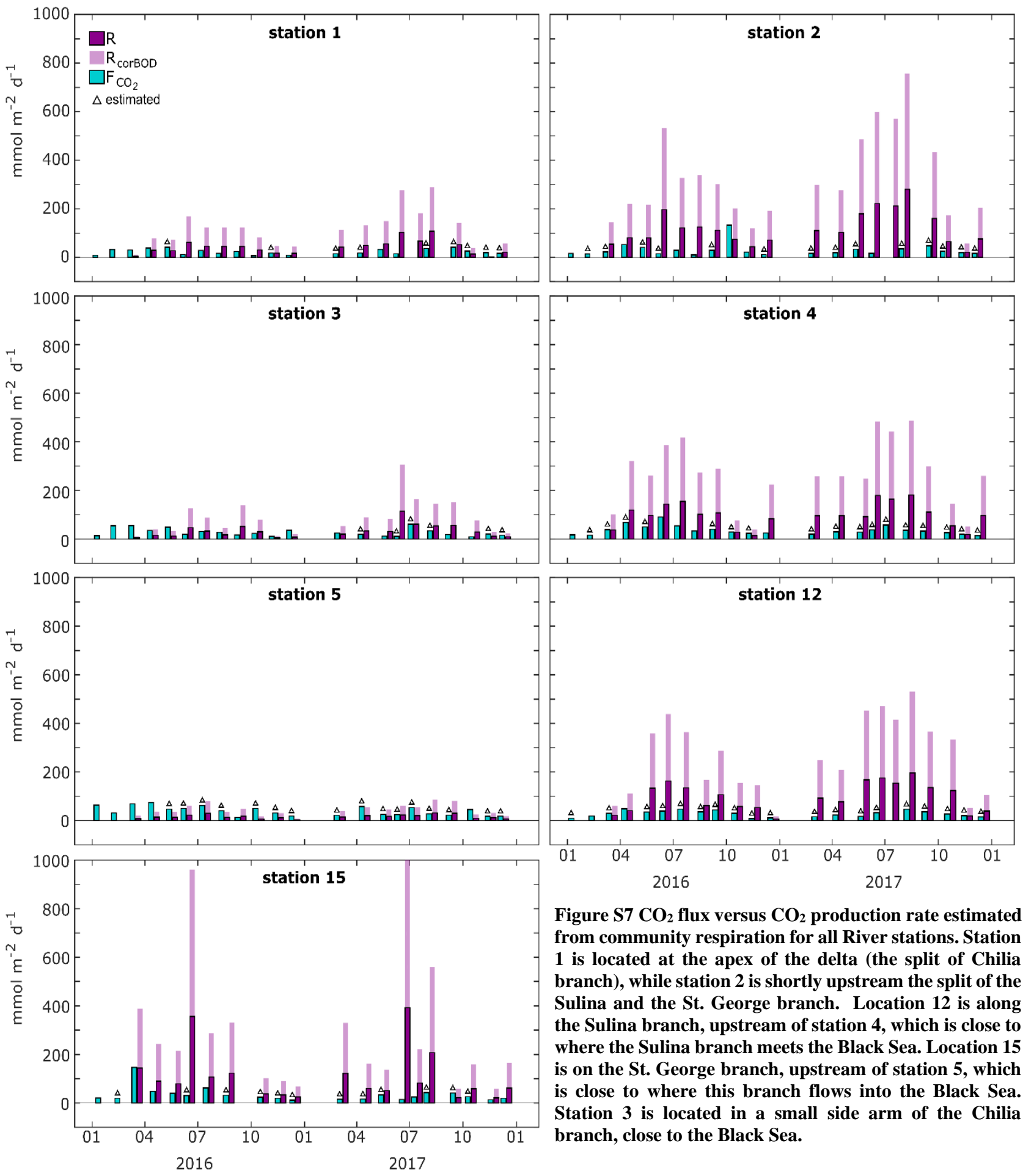

Figure $\mathrm{S}_{7} \mathrm{CO}_{2}$ flux versus $\mathrm{CO}_{2}$ production rate estimated from community respiration for all River stations. Station 1 is located at the apex of the delta (the split of Chilia branch), while station 2 is shortly upstream the split of the Sulina and the St. George branch. Location 12 is along the Sulina branch, upstream of station 4 , which is close to where the Sulina branch meets the Black Sea. Location 15 is on the St. George branch, upstream of station 5, which is close to where this branch flows into the Black Sea. Station 3 is located in a small side arm of the Chilia branch, close to the Black Sea. 


\section{Channel}
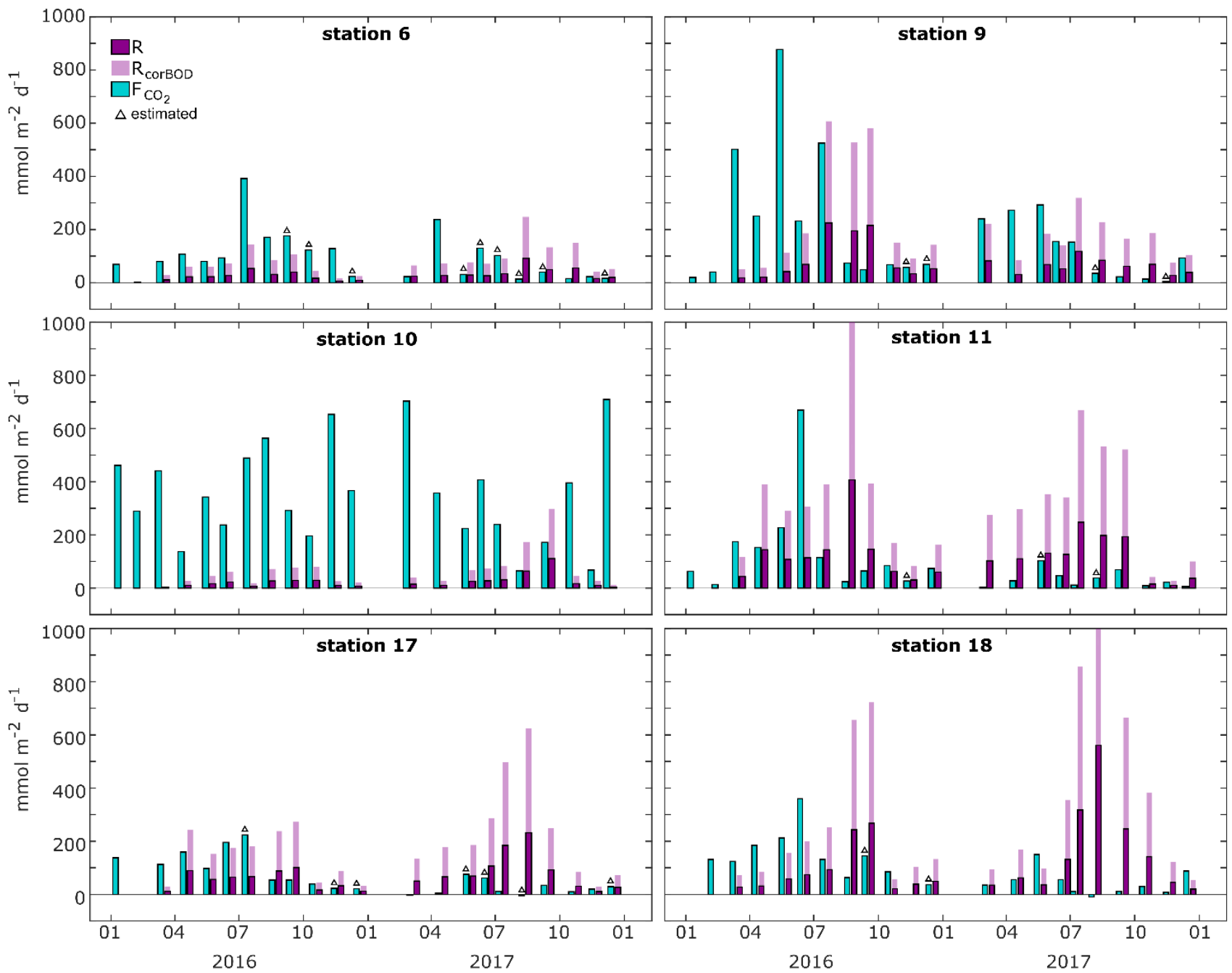

Figure $\mathrm{S} \mathrm{CO}_{2}$ flux versus $\mathrm{CO}_{2}$ production rate estimated from community respiration for all channel stations. Station 6 and 9 are channels draining the delta towards the St.George and the Sulina branch, respectively. Station 10 is located at the border of a UNESCO biosphere reserve core protection zone and represented the $\mathrm{CO}_{2}$ hotspot of this study. Station 11 and station 17 are old meanders of the Sulina branch. Station 18 is leading water from the Sulina branch into the delta. Both station 9 and station 18 are located in channels that are known to reverse flow direction. 


\section{Lake}

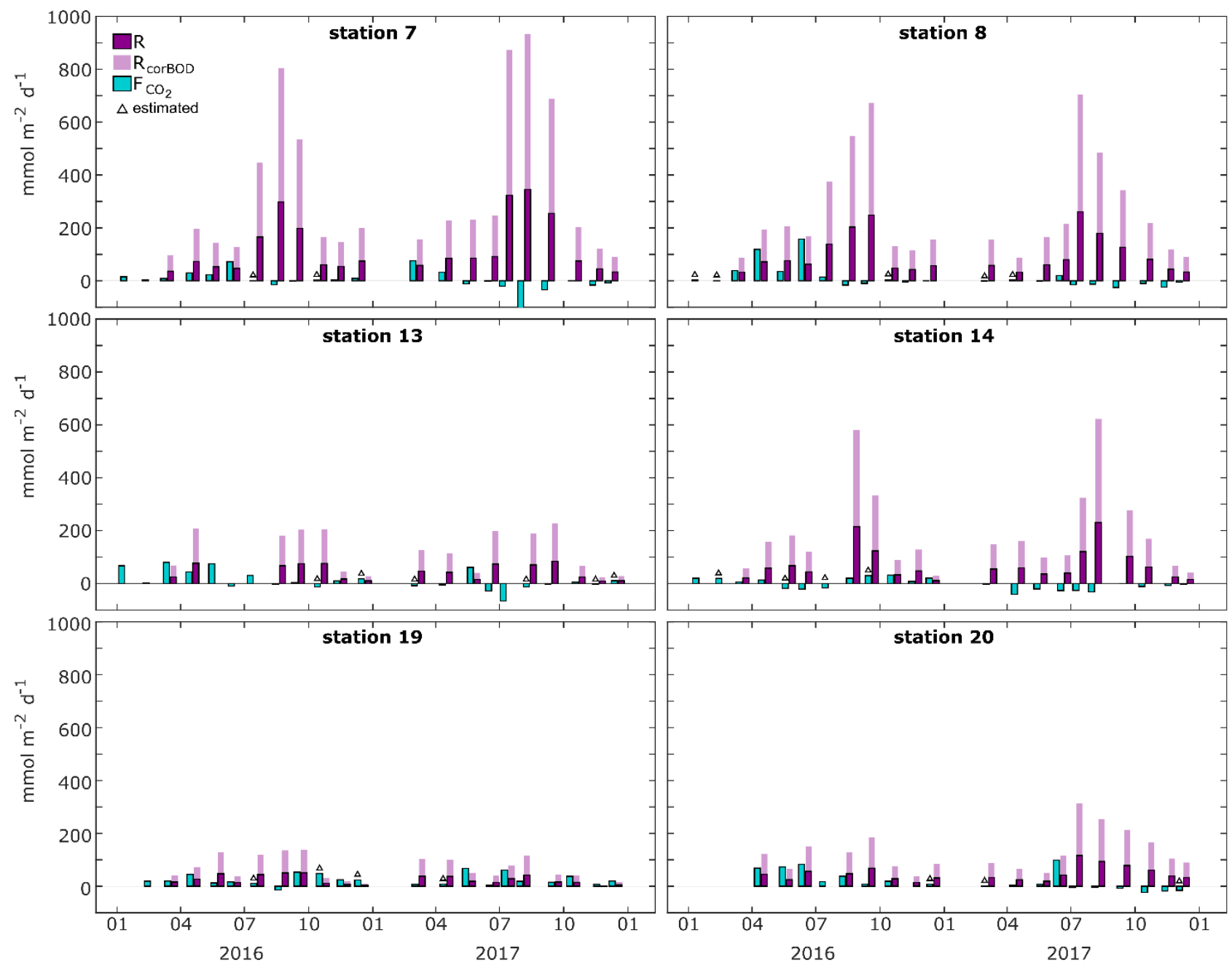

Figure $\mathrm{S} 9 \mathrm{CO}_{2}$ flux versus $\mathrm{CO}_{2}$ production rate estimated from community respiration for all lake stations. Station 14 and 19 are located in the Lake Uzlina-Isac complex, Station 7, 8 and 20 are located in the Lake Puiu-Rosu complex. Lake 13 is the only investigated lake north of the Sulina branch and located in the Matita-Merhei complex. Lake complexes as presented in Oosterberg 5 et al. (2000). 


\section{S3.3.1 Estimating the effect of potential hot spot channels}

One of the channel stations (location 10, Fig. 1 main paper) showed very high $\mathrm{CO}_{2}$ and elevated $\mathrm{CH}_{4}$ concentrations during our observations. This location is draining a region with reed stands that are classified as strictly protected area by the Danube

5 Delta Biosphere Reserve Authority (Fig. S10). The observation station itself is located in the buffer area surrounding the strictly protected area. Considering these two characteristics, i) more or less west-east drainage and ii) connection to either strictly protected area or buffer area, we estimate the fraction of potential hotspot channels to up to $2 \%$ (Fig. S10). This approach assumes the hotspot conditions prevail along the whole channel and not just in the sampled cross-section.

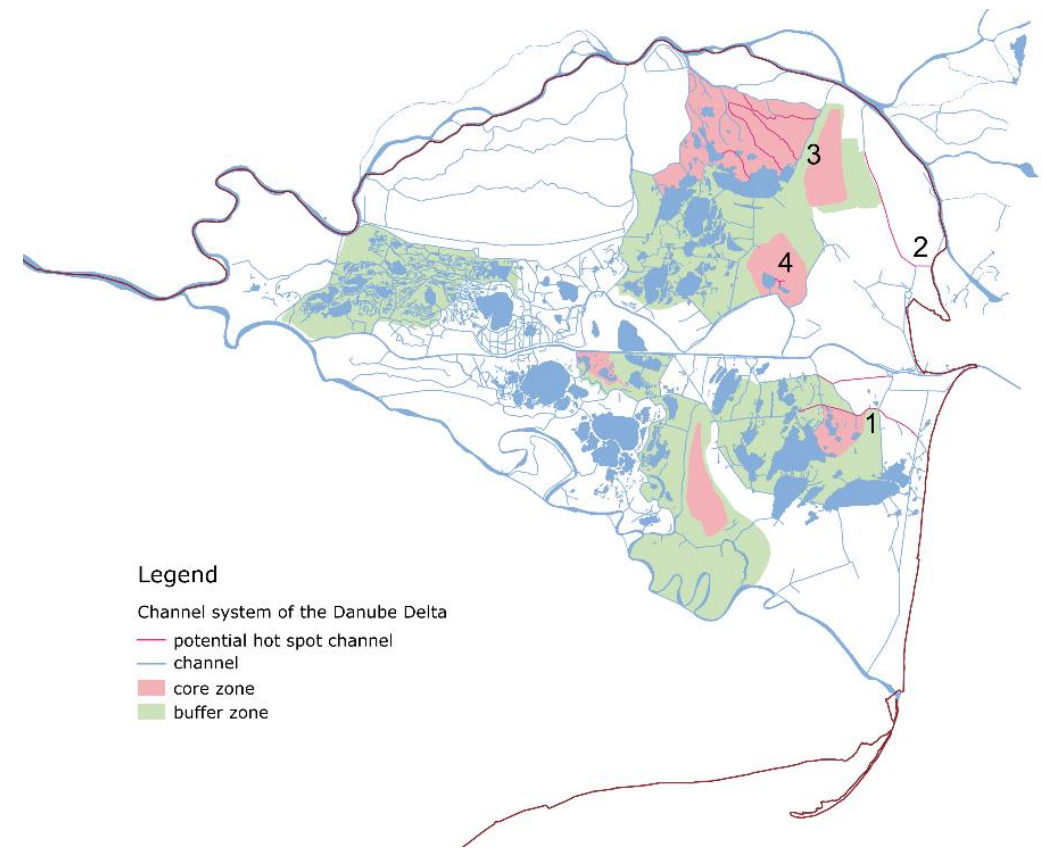

Figure S10 Channel system of the Danube Delta. Potential hotspot channels are indicated in purple. 1) The channel at location 10, where we observed high $\mathrm{CO}_{2}$ concentrations. 2) EXO2 sensor data (not shown in this paper) indicated that this channel also has very high $\mathrm{CO}_{2}$ concentrations. 3) and 4) channels within strictly protected area draining more or less west-east direction. Red and green shaded areas indicate core protection zones (red) and buffer areas (green) of the Danube Delta Biosphere Reserve between the three main branches of the Danube River. Protection zones redrawn from a map of the Danube Delta Biosphere Reserve Authority (2018), shape files for map creation in QGIS adapted from mapcruzin.com (Contains information from www.openstreetmap.org, which is made available here under the Open Database License (ODbL), https://opendatacommons.org/licenses/odbl/1.0/).

Assuming that $2 \%$ of the channels' surface area are hotspots, the upscaling exercise suggests that the hotspots could contribute up to $\sim 20 \%$ to the $\mathrm{CO}_{2}$ and total $\mathrm{CH}_{4}$ fluxes from the channels (Fig. S11 and Table S3). However, the median flux for the channels decreased slightly in this example (cf. Table 2, main text), since the hotspot measurements are no longer pooled with the rest of the channel data and thereby the individual median fluxes used for the calculations of the rest of the channel surface area are slightly lower. 

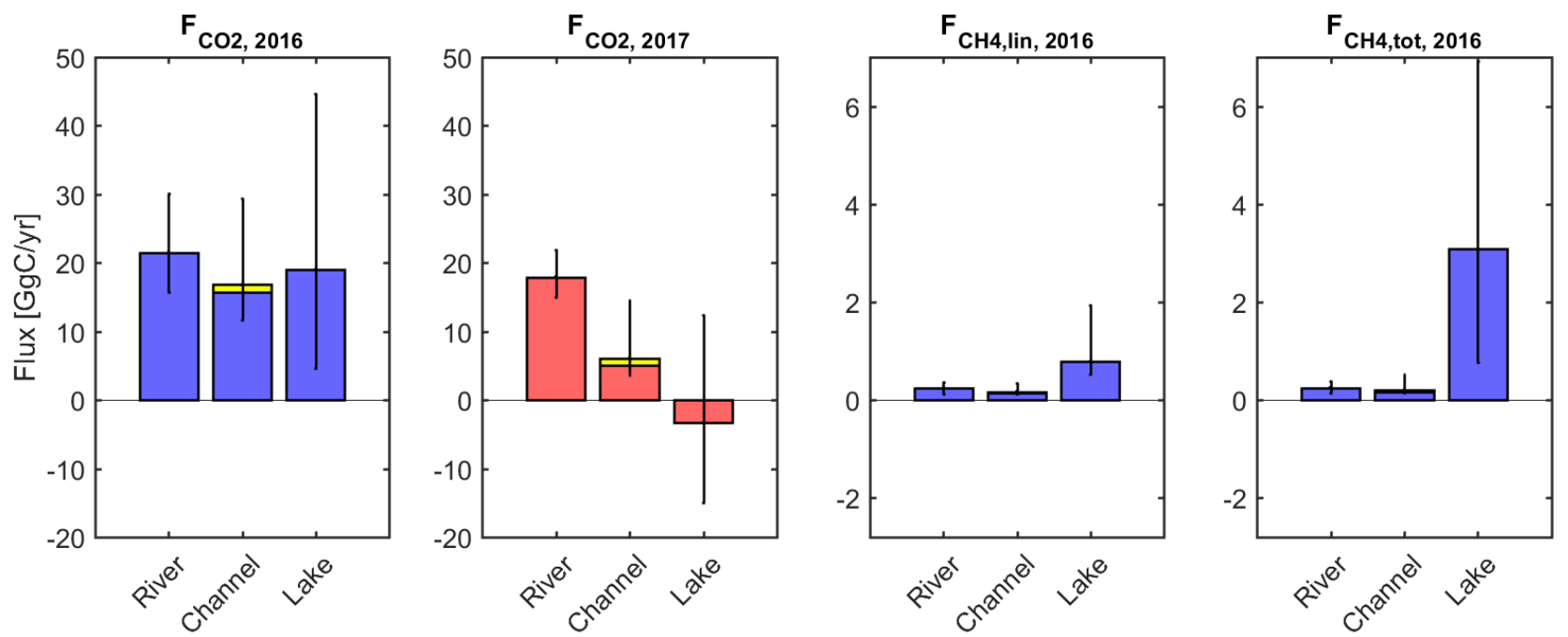

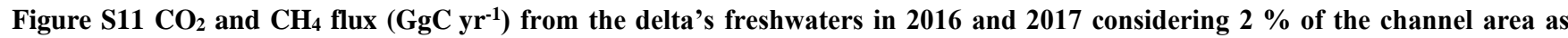
hotspot. The indices lin and tot for $\mathrm{CH}_{4}$ data indicate the diffusive emissions calculated from the linear increase and the total emissions including ebullition. For the channels, contributions from the hotspots are indicated in yellow. In case of $\mathrm{CH}_{4}$, the yellow part of the bar is not visible, yet the hotspots still contribute $14 \%$ and $18 \%$ to the diffusieve and total flux, respectively (see Table S3).

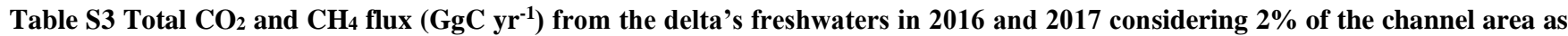
hotspot. For $\mathrm{CH}_{4}$ both diffusive and total fluxes are displayed. Because of large data gaps in $\mathrm{CH}_{4}$ no fluxes were calculated for 2017.

\begin{tabular}{l|cc|ccc|cc}
\hline \multicolumn{1}{c|}{ Flux } & \multicolumn{2}{|c|}{ River } & \multicolumn{3}{c|}{ Channel } & \multicolumn{2}{c}{ Lake } \\
{$\left[\mathbf{G g C ~ y r}^{-1}\right.$ ] } & median & range & median & range & $\begin{array}{c}\text { Frac hot } \\
\text { spot [\%] }\end{array}$ & median & range \\
\hline $\mathbf{C O}_{2, \mathbf{2 0 1 6}}$ & 22 & $16-30$ & 17 & $12-29$ & 6.5 & 19 & $4.6-45$ \\
$\mathbf{C O}_{2, \mathbf{2 0 1 7}}$ & 18 & $15-22$ & 6.1 & $3.7-15$ & 18 & -3.3 & $-15-12$ \\
\hline $\mathbf{C H}_{4, \text { dif, 2016 }}$ & 0.25 & $0.13-0.36$ & 0.17 & $0.12-0.34$ & 14 & 0.79 & $0.52-1.9$ \\
$\mathbf{C H}_{4, \text { tot, 2016 }}$ & 0.25 & $0.15-0.39$ & 0.21 & $0.15-0.53$ & 18 & 3.1 & $0.77-6.9$ \\
\hline
\end{tabular}

\section{S3.3.2 Estimating the effect of potentially isolated lakes}

There are several reports in the literature that refer to some of the delta lakes as "isolated", receiving water from the reed bed and having a long residence time compared to the highly connected lakes. We used the references in Tudorancea and Tudorancea (2006), Covaliov and Coops (2003), the assessment of lake regimes in Oosterberg et al. (2000) and a land use map indicating isolated lakes presented in a report by Doroftei et al. (2013) for our estimation of the surface area of these isolated 15 lakes. 


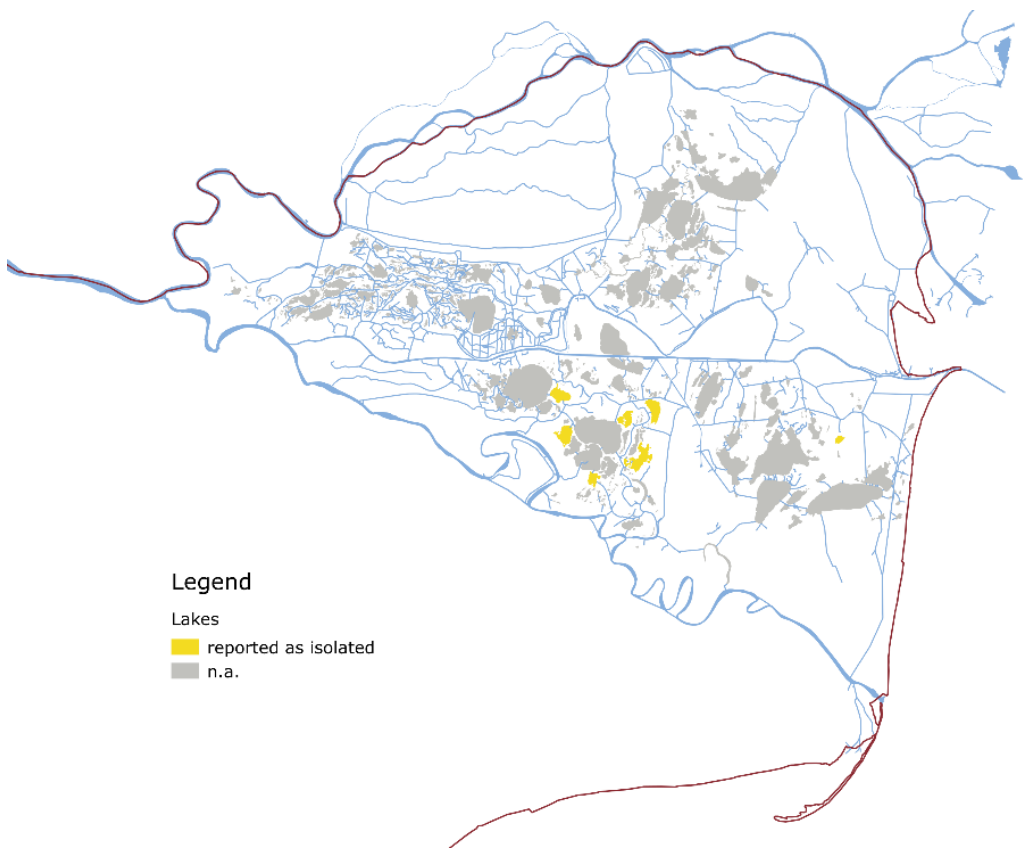

Figure S12 Isolated lakes of the Danube Delta mentioned in Tudorancea and Tudorancea (2006) and Covaliov and Coops (2003). Shape files for map creation in QGIS adapted from mapcruzin.com (Contains information from www.openstreetmap.org, which is made available here under the Open Database License (ODbL), https://opendatacommons.org/licenses/odbl/1.0/). 


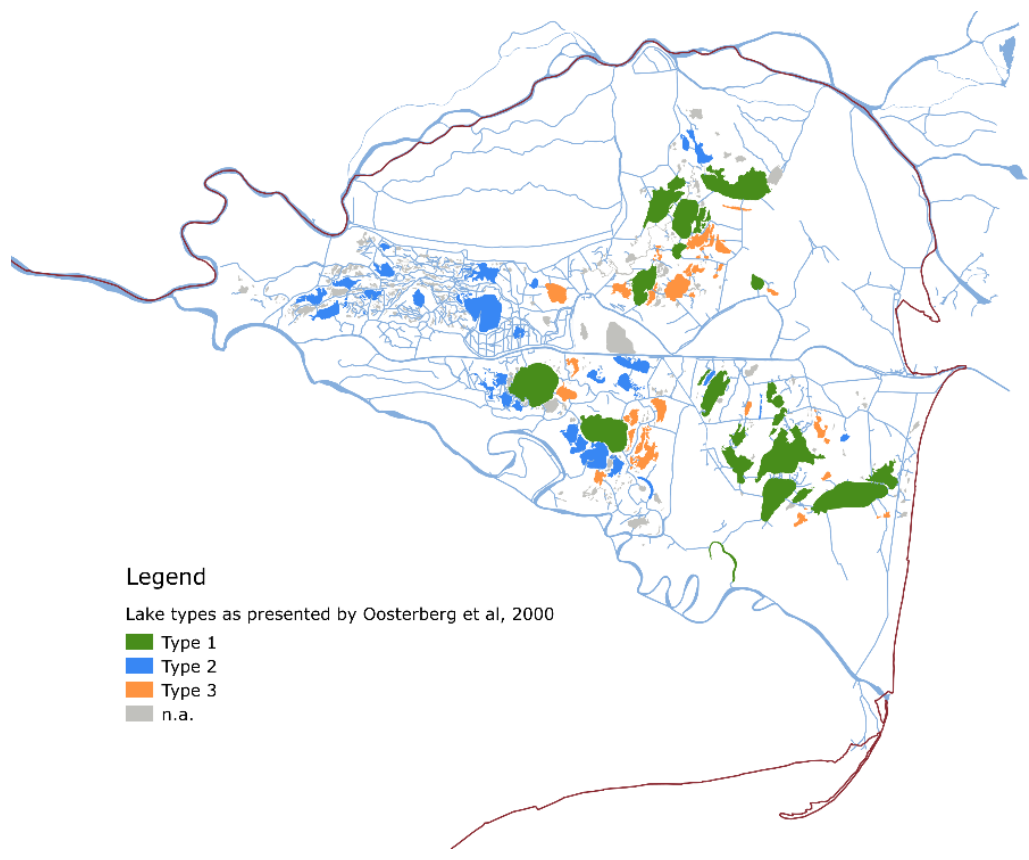

Figure S13 Typology of the delta lakes as presented by Oosterberg et al. (2000). Type 3 refers to isolated lakes with a high organic loading. Shape files for map creation in QGIS adapted from mapcruzin.com (Contains information from www.openstreetmap.org, which is made available here under the Open Database License (ODbL), https://opendatacommons.org/licenses/odbl/1.0/). 


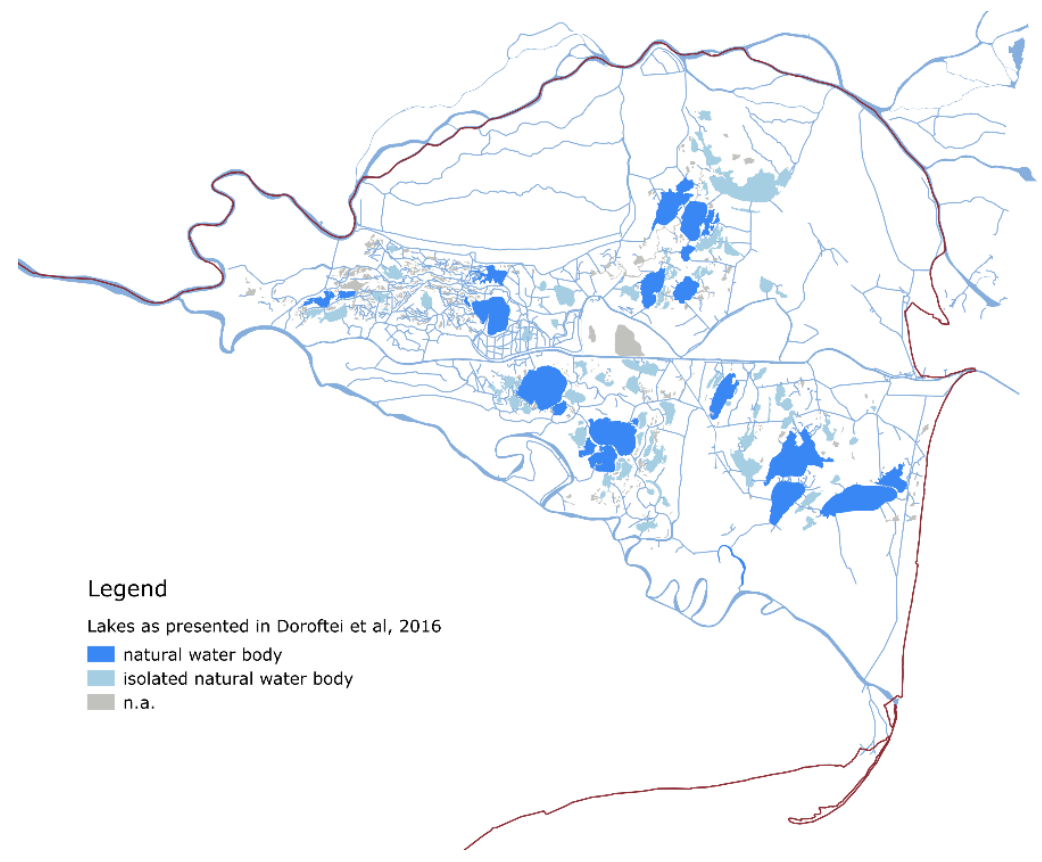

Figure S14 Isolated and non-isolated natural water bodies as presented by Doroftei et al. (2013) based on data from the Danube Delta Biosphere Reserve Authoriy. Shape files for map creation in QGIS adapted from mapcruzin.com (Contains information from www.openstreetmap.org, which is made available here under the Open Database License (ODbL), 5 https://opendatacommons.org/licenses/odbl/1.0/).

The total surface area of the lakes presented as isolated in the above-mentioned studies (see Fig. , \& ) amounts to $99 \mathrm{~km}^{2}$. Studies on very small lakes with surface areas $<0.2 \mathrm{~km}^{2}$ were not present in the literature. While small lakes represent the dominant type of lakes in the delta (75\% of the lakes), their surface area amounts to only $7 \%\left(17.8 \mathrm{~km}^{2}\right)$. These lakes are likely also isolated, yet we do not consider them in the following scenario analysis. Attributing hotspot like flux characteristics to the

10 isolated lakes $\left(\mathrm{A}=99 \mathrm{~km}^{2}\right)$, indicates that they could strongly increase both $\mathrm{CO}_{2}$ and $\mathrm{CH}_{4}$ fluxes from the lakes and also reverse the potential sink capacity of the lakes in 2017 (Fig. 5 main text and Fig. ). It is however unlikely that all isolated lakes have fluxes as high as the hotspot, so the evaluation of this scenario represents an upper boundary to the potential fluxes from these poorly characterized, isolated systems. 

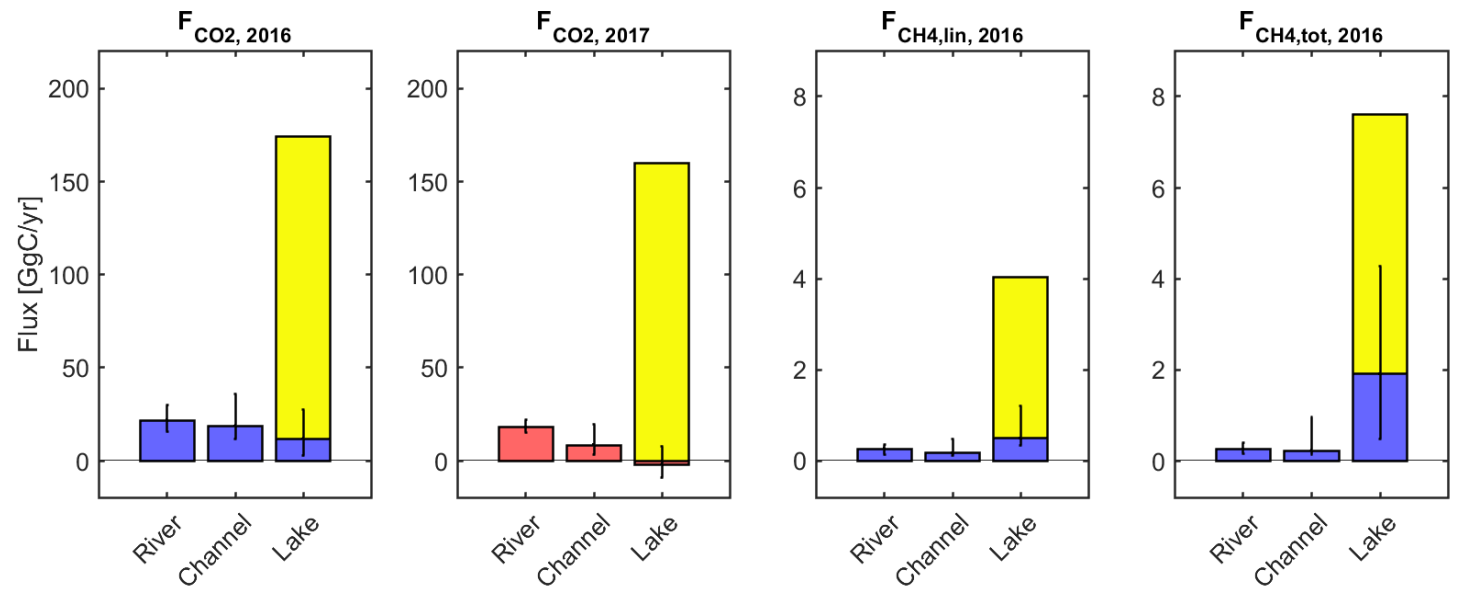

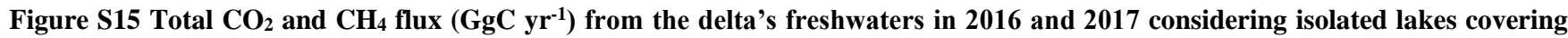
$99 \mathrm{~km}^{2}$ as characterized by hotspot like fluxes. Estimated upper boundary for the contributions from the isolated lakes are shown in yellow.

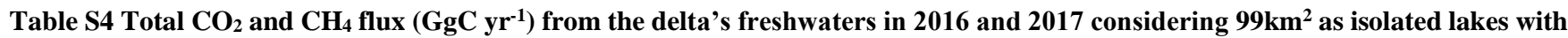
hotspot like fluxes. For $\mathrm{CH}_{4}$ both diffusive and total fluxes are displayed. Because of large data gaps in $\mathrm{CH}_{4}$ no fluxes were calculated for 2017.

\begin{tabular}{c|cc|cc|ccc}
\hline Flux & \multicolumn{2}{|c|}{ River } & \multicolumn{2}{c|}{ Channel } & \multicolumn{3}{c}{ Lake } \\
{$\left[\mathbf{G g C ~ y r}^{-1}\right]$} & median & range & median & range & median & range & $\begin{array}{c}\text { Frac } \\
\text { isoLakes } \\
{[\%]}\end{array}$ \\
\hline $\mathbf{C O}_{\mathbf{2 , 2 0 1 6}}$ & 22 & $16-30$ & 19 & $12-36$ & 174 & $165-190$ & 93 \\
$\mathbf{C O}_{2, \mathbf{2 0 1 7}}$ & 18 & $15-22$ & 8.4 & $3.0-19$ & 158 & $150-167$ & $101^{\mathrm{a}}$ \\
\hline $\mathbf{C H}_{4, \text { dif, 2016 }}$ & 0.25 & $0.13-0.36$ & 0.16 & $0.11-0.48$ & 4.0 & $3.9-4.7$ & 88 \\
$\mathbf{C H}_{4, \text { tot, 2016 }}$ & 0.25 & $0.15-0.39$ & 0.22 & $0.13-0.95$ & 7.6 & $6.2-10$ & 75 \\
\hline
\end{tabular}

a isolated lakes counteract the sink capacity of the flow-through lakes in this case. 


\section{References}

Beaulieu, J. J., McManus, M. G., and Nietch, C. T.: Estimates of reservoir methane emissions based on a spatially balanced probabilistic-survey, Limnology and Oceanography, 61, S27-S40, 10.1002/lno.10284, 2016.

Covaliov, S., and Coops, H.: Seasonality of aquatic vegetation in the Danube Delta, Institute for Inland Water Management 5 and Waste Water Treatment RIZA, 2003.

DDBRA Map: http://www.ddbra.ro/en/ddbra-map, access: 2018, 2018.

Doroftei, M., Mierla, M., Silviu, C., Nanu, C., and Lupu, G.: HABIT-CHANGE: Climate change adapted management plan for Danube Delta Biosphere Resereve, 2013.

ICPDR: Danube River Basin Water Quality Database, http://www.icpdr.org/wq-db/, 2018.

10 mapcruzin.com, https://mapcruzin.com/free-romania-arcgis-maps-shapefiles.htm, based on www.openstreetmap.org/, 2016. Oosterberg, W., Staras, M., Bogdan, L., Buijse, A. D., Constantinescu, A., Coops, H., Hanganu, J., Ibelings, B. W., Menting, G. A. M., and Navodaru, I.: Ecological gradients in the Danube Delta lakes: present state and man-induced changes, 2000. Tudorancea, C., and Tudorancea, M. M.: Danube Delta: genesis and biodiversity, Backhuys Publishers, Leiden, 2006.

Ward, N. D., Sawakuchi, H. O., Neu, V., Less, D. F. S., Valerio, A. M., Cunha, A. C., Kampel, M., Bianchi, T. S., Krusche, 15 A. V., Richey, J. E., and Keil, R. G.: Velocity-amplified microbial respiration rates in the lower Amazon River, Limnology and Oceanography Letters, 3, 265-274, https://doi.org/10.1002/lol2.10062, 2018. 